\title{
Session 4: Molecular biology I
}

\author{
Monday 29th October 2007. Moderators: Jim W. Larrick and Sachdev Sidhu
}

[16.00-16.30]

\section{Insights into molecular recognition from minimalist synthetic antibodies}

Sachdev S. Sidhu

Department of Protein Engineering, Genentech Inc, 1 DNA Way, South San Francisco, CA 94080, USA

Antibodies can evolve to recognize essentially any protein with high specificity and affinity. While natural antigen binding sites utilize all 20 natural amino acids to some extent, analysis of functional antibodies reveals clear biases for or against some amino acids. Most significantly, tyrosine and serine are highly abundant in antigen binding sites in general and at antigen contact sites in particular.

As it is now possible to construct antibody-phage libraries with synthetic diversity, we have used synthetic antibody libraries to investigate the roles of different chemical diversity in antigen recognition. Using a tetranomial genetic code that allows for only four amino acids (tyrosine, serine, alanine, and aspartate) we were able to generate antibodies against vascular endothelial growth factor (VEGF) that bound with high affinity and specificity. Structural and mutational analyses indicated that tyrosine was the major mediator of binding energy at the antigen binding sites of the antiVEGF Fabs, and the results suggested that it might be possible to further simplify the code for antigen recognition. To this end, we constructed Fab libraries in which combining sites were randomized with a binary genetic code that allowed for only tyrosine and serine. We envisioned that in these libraries, tyrosine might act as an effective "functional" amino acid with a large side chain that could provide significant binding contacts. In contrast, serine might act as an "auxiliary" amino acid with a small side chain that could provide space for the tyrosine side chains and also contribute to an overall hydrophilic surface.

Remarkably, naïve Fab libraries constructed with the binary code were extremely effective in generating highly specific antibodies against a wide array of antigens. Furthermore, the binary Fabs exhibited exquisite specificity in cell-based assays. The structures of binary Fabs in complex with antigen reveal that the highly homogenous binding surfaces are dominated by tyrosine, but nonetheless, recognize diverse chemical groups on the antigen. In ongoing studies, we are now adding back chemical and conformational diversity into the minimalist binary background in a precisely defined manner, and these highly controlled studies will enable the accurate assessment of the consequences of expanded diversity.

Our results suggest that certain amino acids possess features that increase the likelihood that they will be able to make productive contributions to binding affinity and specificity. Thus, biased libraries that favour such amino acids are likely to be much more effective in generating antibodies with high affinity and specificity. As a corollary, it seems that other amino acids are ill suited for productive contacts, and the absence or depletion of such amino acids will likely improve naïve antigen recognition. The results should aid the design and use of synthetic antibody libraries. In addition, and perhaps more importantly, the findings have significant implications for the fundamental principles and mechanisms that mediate molecular recognition at protein-protein interfaces.

\section{[16.30-16.50]}

Human CD32B (Fe $\gamma$ RIIB): A multifaceted target for enhanced antibody therapeutics Syd Johnson Antibody Engineering, MacroGenics, Inc., Rockville, $M D, U S A$

Receptors specific for the Fc portion of immunoglobulins link humoral responses to effector functions, both beneficial and idiopathic. CD32B (Fc-gamma-RIIB), the only inhibitory $\mathrm{Fc}$ receptor, is present at high levels 
on B cells and at lower levels on monocytes, dendritic cells, basophils and mast cells. CD32B counterbalances signaling through an activating receptor; including the BCR, activating Fc-gamma-R, or Fc-epsilon-R, on the corresponding cell types. We have generated, characterized and humanized several $\mathrm{mAbs}$ which bind with exquisite specificity to CD32B but not the closely related activating receptor, $\mathrm{CD} 32 \mathrm{~A}$. This is the first time such selective antibodies have been described and their use has led to a greater understanding of the expression patterns and functional properties of these two receptors in normal and diseased tissues. We are also developing biologic agents to take advantage of the pattern of expression of CD32B and its inhibitory function therapeutically in oncology, autoimmunity and allergy. We have utilized Fc-engineering and a novel bispecific format to exploit several facets of $\mathrm{CD} 32 \mathrm{~B}$ as a therapeutic target. The resulting molecules are highly active in vitro and potent in vivo, as shown in several FcRtransgenic mouse models. A newly developed expression system allowing for secretion of antibody fragments by E. coli and full length mAbs or sFv-Fc fusion proteins in mammalian cells, without reformatting, will also be described.

\section{References}

[1] M.C. Veri et al., Monoclonal antibodies capable of discriminating the human inhibitory Fcgamma-receptor IIB (CD32B) from the activating Fcgamma-receptor IIA (CD32A): biochemical, biological and functional characterization, Immunology Mar 26 (2007), [Epub ahead of print].

[2] T.R. Radstake et al., The functional variant of the inhibitory Fcgamma receptor IIb (CD32B) is associated with the rate of radiologic joint damage and dendritic cell function in rheumatoid arthritis, Arthritis Rheum 54(12) (2006), 3828-38237.

[3] C.T. Rankin et al., CD32B, the human inhibitory Fc-gamma receptor IIB, as a target for monoclonal antibody therapy of B-cell lymphoma, Blood 108(7) (2006), 2384-2391.

[4] M. Mackay et al., Selective dysregulation of the FcgammaIIB receptor on memory B cells in SLE, J Exp Med 203(9) (2006), 2157-2164.

[5] A.M. 4Boruchov et al., Activating and inhibitory IgG Fc receptors on human DCs mediate opposing functions, J Clin Invest 115(10) (2005), 2914-2923.

[6] K.M. Dhodapkar et al., Selective blockade of inhibitory Fcgamma receptor enables human dendritic cell maturation with IL12 p70 production and immunity to antibody-coated tumor cells, Proc Natl Acad Sci USA 102(8) (2005), 2910-2915.

[7] S. Johnson and L. Huang, Dual expression vector system for antibody expression in bacterial and mammalian cells, United States Patent 7 (2006), 112,439.

[16.50-17.10]

Humanization of a highly stable anti-lysozyme scFv endowed with intracellular functionality. A single framework residue dramatically affects protein expression and stability

Marcello Donini $^{\mathrm{a}}$, Maria Elena Villani ${ }^{\mathrm{a}}$, Veronica Morea $^{\mathrm{b}}$, Valerio Consalvi ${ }^{\mathrm{c}}$, Roberta Chiaraluce ${ }^{\mathrm{c}}$, Angiola Desiderio $^{\mathrm{a}}$ and Eugenio Benvenuto ${ }^{\mathrm{a}}$ ${ }^{a}$ ENEA,UTS Biotecnologie, Sezione Genetica e Genomica Vegetale, C.R. Casaccia, P.O. Box 2400 I-00100 Roma, Italy ${ }^{\mathrm{b}}$ CNR Institute of Molecular Biology and Pathology ${ }^{\mathrm{c}}$ Department of Biochemical Sciences, University "La Sapienza”, P.le Aldo Moro 5, 00185 Rome, Italy E-mail: marcello.donini@casaccia.enea.it

Introduction: In recent years the number of recombinant antibodies aimed at diagnostic and therapeutic applications has been increasing [1] and the single-chain variable domain fragment ( $\mathrm{scFvs}$ ) in particular, resulted one of the most successful antibody formats developed until now [2]. It is comprised of the variable regions of both the heavy and light chains, bearing the antigen binding site (ABS), joined together by a flexible linker that allows the expression as a single polypeptide sequence. The main advantages of these molecules over complete immunoglobulins include the ease of expression in different biological systems and the higher speed of tissue uptake and blood clearance. All of these properties are particularly useful in tumour targeting and for in vivo imaging purposes, so that several scFvs and scFv-containing molecular complexes are now undergoing clinical or preclinical studies [1]. The intrinsic thermodynamic stability of candidate therapeutic antibody fragments is considered an important requisite for in vivo applications since it correlates with favourable pharmacokinetic properties as well as with their functionality inside the cell $[3,4,5]$, where they can modulate the function of proteins and intracellular pathogens [6] and target molecular processes associated with carcinogenesis [7]. Together with a high thermodynamic stability, another essential requisite for applications of antibody fragments in human therapy is that they should possess a low immunogenic potential. Indeed, a major obstacle hampering the use of antibody fragments of murine origin for human therapy concerns their potential to raise adverse immune responses in patients [8], such that most of the recombinant antibodies that reached pre-clinical or clinical trials are either of human origin or, in case they originated from different animal sources (usually rodent), they had been previously humanized, by replacing molecule regions that are not involved in antigen binding with homologous regions from human antibodies. In this 
(A)
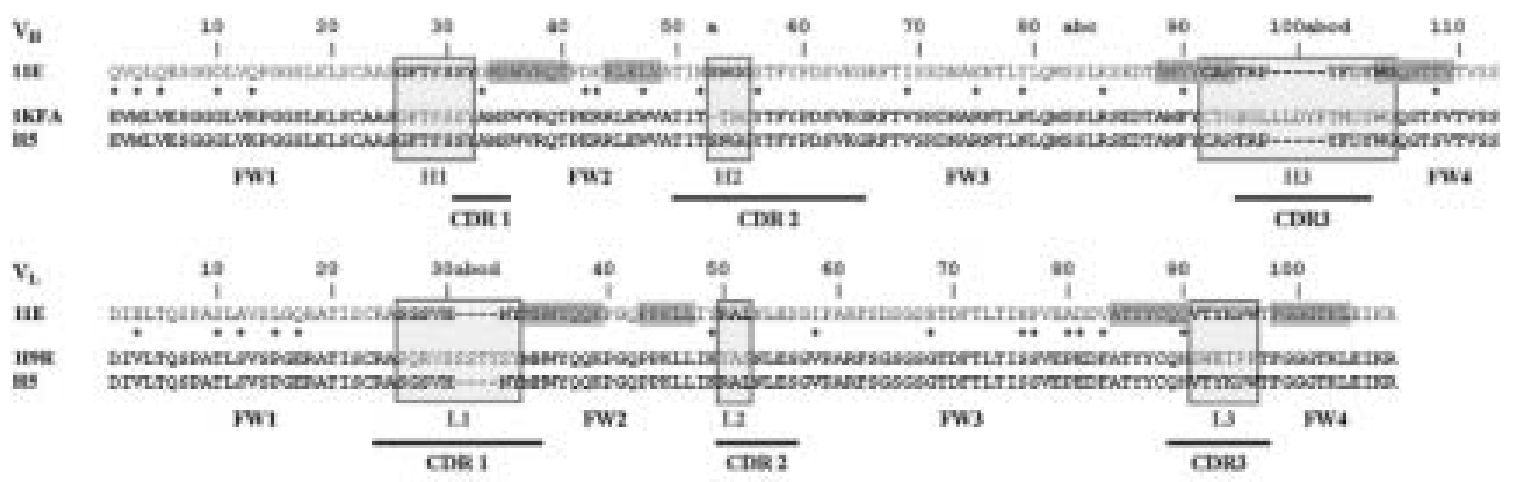

(B)
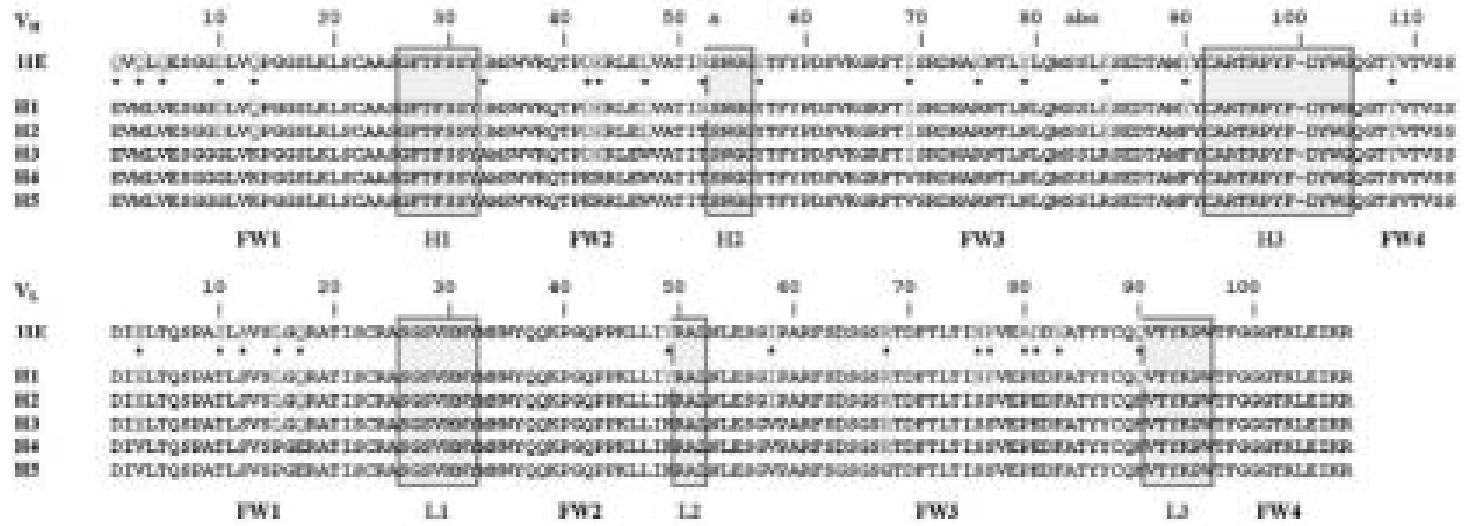

Fig. 1. Sequence alignment of $\mathrm{V}_{H}$ and $\mathrm{V}_{L}$ domains used for the humanisation of $\mathrm{scFv}(11 \mathrm{E})$.(A) Sequence alignment between the $\mathrm{V}_{H}$ and $\mathrm{V}_{L}$ domains of the murine anti-HEL ABS-donor $\mathrm{scFv}(11 \mathrm{E})$, the homologous ABS-acceptor domains from antibodies of human origin (PDB IDs: $1 \mathrm{KFA}$ and $1 \mathrm{I} 9 \mathrm{R}$, respectively) and the designed humanised $\operatorname{scFv}(\mathrm{H} 5)$. (B) Sequence alignment between the $\mathrm{V}_{L}$ and $\mathrm{V}_{H}$ domains of the murine anti-HEL ABS-donor $\mathrm{scFv}(11 \mathrm{E})$, the intermediate $\mathrm{scFv}$ products $\mathrm{scFv}(\mathrm{H} 1), \mathrm{scFv}(\mathrm{H} 2), \mathrm{scFv}(\mathrm{H} 3)$ and $\mathrm{scFv}(\mathrm{H} 4)$, and the designed, fully humanised scFv(H5). Residue numbering, hypervariable loops, key-residues, CDRs and Fw regions are indicated as in Figure 1A. Non-identical Fw residues between $\mathrm{scFv}(11 \mathrm{E})$ and $\mathrm{scFv}(\mathrm{H} 5)$ are indicated by asterisks. Residues identical to and different from those present in scFv(H5) are bold and highlighted yellow, respectively.

work, our aim was to obtain a scFv scaffold endowed with the same favourable properties (i.e., high stability and intracellular functionality) of the $\operatorname{scFv}(\mathrm{F} 8)[5,9]$ and devoid of the potential immunogenicity associated with its murine origin. To this end, we humanized the anti-lysozyme scFv(11E) obtained from a phagedisplay library, which has the same framework regions and favourable properties as the $\mathrm{scFv}(\mathrm{F} 8)[10]$.

Humanization design: The humanized $\mathrm{scFv}(11 \mathrm{E})$ was designed by joining the ABS of the $\operatorname{scFv}(11 \mathrm{E})$ (ABS-donor) with the $\mathrm{Fw}$ regions of human origin (ABS-acceptors) showing the highest sequence identity with the Fw regions of $\mathrm{scFv}(11 \mathrm{E})$.

The selected ABS acceptors were the 4-B8(8)/E9 Fab $\left(\mathrm{V}_{H} 3\right.$ fr1 subtype II, $82 \%$ sequence identity with $\operatorname{scFv}(11 \mathrm{E}) \mathrm{V}_{H}$ domain) and humanized $5 \mathrm{c} 8 \mathrm{Fab}\left(\mathrm{V}_{k} \mathrm{III}\right.$ subgroup, $85 \%$ sequence identity with $\operatorname{scFv}(11 \mathrm{E}) \mathrm{V}_{L}$ domain), respectively. For both Fabs a crystallographic structure was available from the Protein Data Bank
(PDB), with identifiers (ID) 1KFA [11] Resolution =

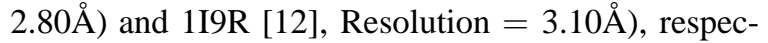
tively. The high sequence identity between the murine ABS donor $\mathrm{scFv}(11 \mathrm{E})$ and the selected $\mathrm{ABS}$ acceptors of human origin (higher than $80 \%$ for both $\mathrm{V}_{L}$ and $\mathrm{V}_{H}$ Fw regions) has been previously shown to correspond to a high structural conservation (i.e., RMSD $<1.0 \AA$ ) in the core regions of homologous proteins [13]. Therefore, the main-chain conformation of the $\mathrm{FW}$ regions of the ABS-donor $\operatorname{scFv}(11 \mathrm{E})$ and $\mathrm{ABS}$ acceptor $\mathrm{V}_{L}$ and $\mathrm{V}_{H}$ domains is expected to be essentially the same and to be maintained in the fully humanized $\mathrm{scFv}(\mathrm{H} 5)$, comprising the same $\mathrm{FW}$ regions as the ABS-acceptor $\mathrm{V}_{L}$ and $\mathrm{V}_{H}$ domains (Fig. 1).

Construction and analysis of the of the humanized $s c F v$ : The designed $\mathrm{scFv}(\mathrm{H} 5)$ sequence was obtained by stepwise mutagenesis of the $\operatorname{scFv}(11 \mathrm{E}) \mathrm{Fw}$ regions. The mutagenesis and cloning strategy led to the generation of four intermediate $\mathrm{scFv}$ products 
$\boldsymbol{A}$

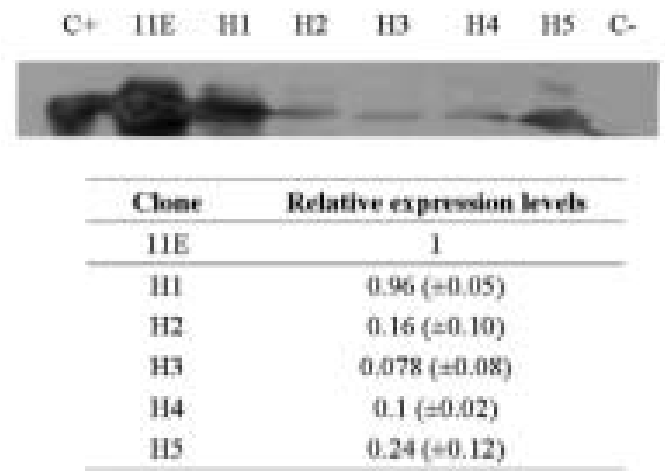

C

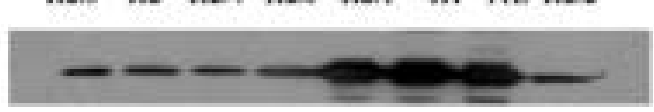

B

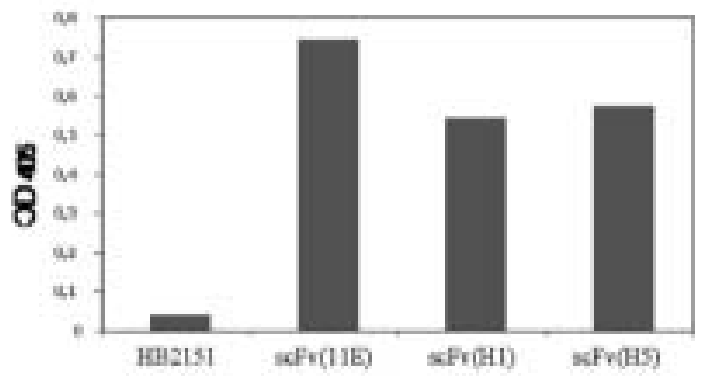

\begin{tabular}{cc}
\hline Clvee & Relative espression levels \\
\hline HE & 1 \\
\hline HI & $0.95(10.05)$ \\
$H 2.1$ & $0.59(+0.02)$ \\
$H 2.2$ & $0.37(+0.09)$ \\
$H 2.3$ & $0.37(+0.14)$ \\
$H 2.4$ & $0.33(10.10)$ \\
$H 2.5$ & $0.12(10.10)$ \\
$H 2$ & $0.21( \pm 0.15)$ \\
\hline
\end{tabular}

Fig. 2. Analysis of the mutagenised scFvs expressed in a soluble form in the periplasm. (A) Soluble periplasmic expression of the four intermediate clones $\mathrm{scFv}(\mathrm{H} 1)-(\mathrm{H} 4)$ and of the fully humanised $\mathrm{scFv}(\mathrm{H} 5)$. Extracts were normalized for total protein content and analysed by reducing SDS-PAGE. Relative expression levels of the analyzed clones were determined by densitometric analysis of three independent western blot results. Values reported in the tables represent the mean of three independent experiments with standard deviations. The scFv(11E) value was arbitrarily set to 1 .Twenty nanograms of purified $\mathrm{scFv}(11 \mathrm{E})$ were used as a positive control $(\mathrm{C}+)$, while untransformed E. Coli HB2151 periplasmic extract was used as a negative control (C-). (B) HEL binding activity of the $\mathrm{scFv}(11 \mathrm{E})$, scFv(H1) and scFv(H5) periplasmic extracts were assayed by ELISA as described in materials and methods. Reported absorbance values were obtained after 30 min incubation. Extracts from untransformed E. coli HB2151 cells were used as a negative control. (C) Soluble periplasmic expression of the five intermediate scFv clones obtained following mutagenesis of $\operatorname{scFv}(\mathrm{H} 1)$. Extracts were normalized for total protein content and relative expression levels were determined by densitometric analysis of three independent western blot results. Twenty nanograms of purified scFv(11E) were used as a positive control $(\mathrm{C}+)$.

named $\operatorname{scFv}(\mathrm{H} 1), \operatorname{scFv}(\mathrm{H} 2), \operatorname{scFv}(\mathrm{H} 3)$ and $\operatorname{scFv}(\mathrm{H} 4)$, as well as to the fully humanized $\mathrm{scFv}(\mathrm{H} 5)$ (Fig. 1B). All scFv variants were analysed for expression yields in a soluble form in the periplasm of E. coli. As shown in Fig. 2A, only $\operatorname{scFv}(\mathrm{H} 1)$ showed expression levels similar to those observed for $\operatorname{scFv}(11 \mathrm{E})$, clones $\mathrm{scFv}(\mathrm{H} 2), \mathrm{scFv}(\mathrm{H} 3), \mathrm{scFv}(\mathrm{H} 4)$ and $\mathrm{scFv}(\mathrm{H} 5)$ showing expression yields 4 to 13 times lower. $\mathrm{ScFv}(\mathrm{H} 1)$ and $\mathrm{scFv}(\mathrm{H} 5)$ were purified from the periplasmic extract to further characterize their immunological properties. Purification yields for $\mathrm{scFv}(\mathrm{H} 5)$ proved to be very low (about $30-40 \mu \mathrm{g} / \mathrm{L}$ bacterial culture) while for $\mathrm{scFv}(\mathrm{H} 1)$ they were in the same range as $\mathrm{scFv}(11 \mathrm{E})$ (about $1 \mathrm{mg} / \mathrm{L}$ ). Functional analysis of the periplas- mic extracts of $\mathrm{scFv}(\mathrm{H} 1)$ and $\mathrm{scFv}(\mathrm{H} 5)$ using ELISA showed that both possessed a specific binding activity for HEL (Fig. 2B).

Effects of a single mutation on the soluble expression levels of the fully humanized $s c F v(H 5)$ and of the $s c F v(H 2)$ intermediate: To identify residues potentially responsible for the drop in expression levels between $\operatorname{scFv}(\mathrm{H} 1)$ and $\operatorname{scFv}(\mathrm{H} 2)$, we analysed the expression profile of the five intermediate clones obtained by mutagenesis between these two molecules. As shown in Figure 2C, the expression levels of the intermediate clones decrease about three to eight-fold compared to $\operatorname{scFv}(\mathrm{H} 1)$, with the exception of $\operatorname{scFv}(\mathrm{H} 2.1)$, which differs from $\mathrm{scFv}(\mathrm{H} 1)$ by only two residues and 


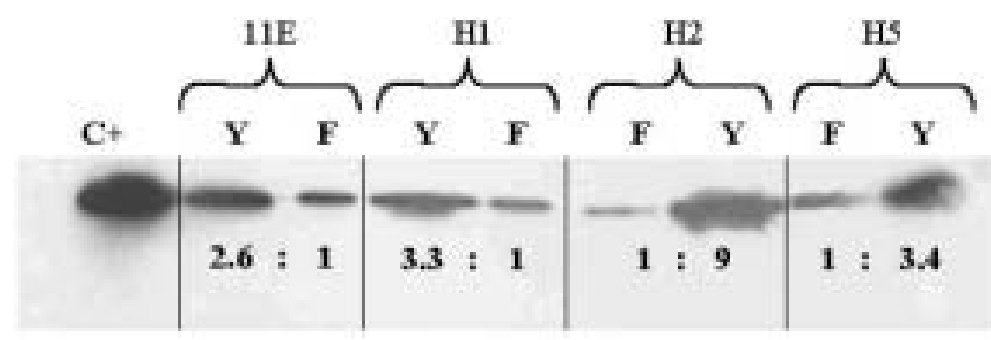

Fig. 3. Western blot analysis of the periplasmic expression levels of $\mathrm{scFv}(11 \mathrm{E}), \mathrm{scFv}(\mathrm{H} 1), \mathrm{scFv}(\mathrm{H} 2)$ and $\mathrm{scFv}(\mathrm{H} 5)$ and of their $\mathrm{H} 90$ mutants. $\mathrm{F}$ and $\mathrm{Y}$ indicate the amino acid residue present at position H90. Protein extracts of each clone were normalized for total protein content and analysed by reducing SDS-PAGE. Relative expression levels of the analyzed scFvs determined by densitometric analysis are indicated. Purified $\operatorname{scFv}(11 \mathrm{E})(20 \mathrm{ng})$ was used as a positive control.

A

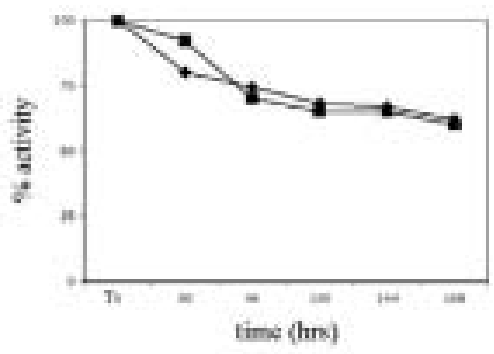

B

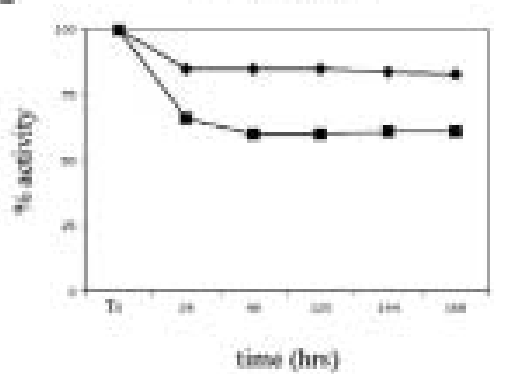

scFu(1IF)

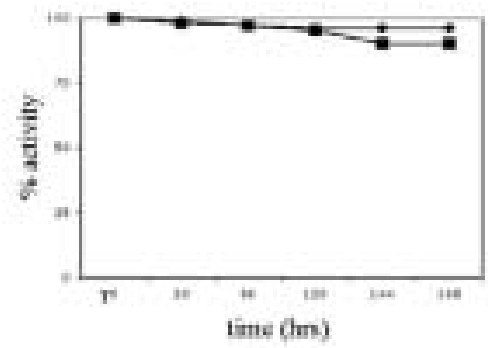

sFu(IIF)

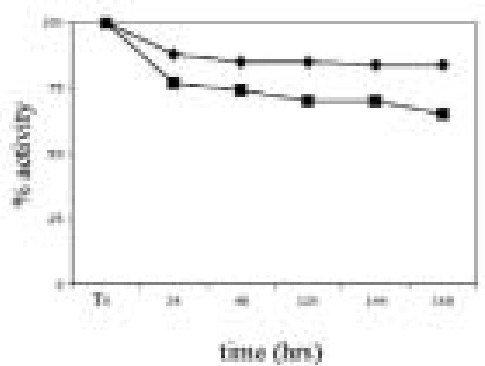

scFu(DI.3)

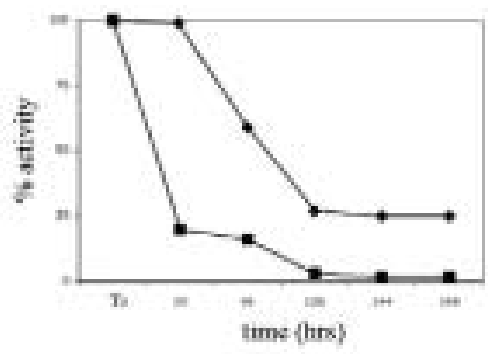

SCFY(DI.3)

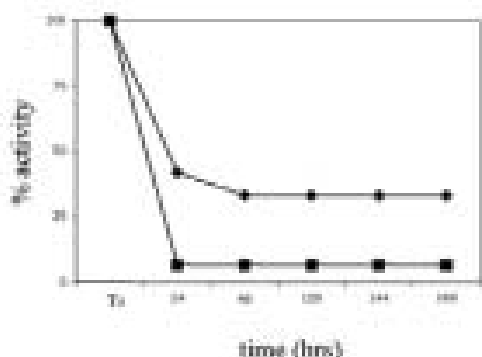

Fig. 4. Stability of the final humanized $\mathrm{scFv}(\mathrm{H} 5) \mathrm{H} 90 \mathrm{Y}$, $\mathrm{scFv}(11 \mathrm{E})$ (used as a highly stable $\mathrm{scFv}$ control) and $\mathrm{scFv}(\mathrm{D} 1.3)$ (used as a poorly stable scFv control) in serum and phosphate buffer. The scFvs were incubated at $4{ }^{\circ} \mathrm{C}$ and $37^{\circ} \mathrm{C}$ for various time period (up to 168 hours) either in PBS (A) or in human serum (B). Antigen binding activity (RU) was determined by SPR on a HEL coated chip. Residual activity was determined at each time point as follows: $\mathrm{RU}$ of the scFv sample treated with $\mathrm{PBS}$ or human serum at $3{ }^{\top} \mathrm{C}$ or $4^{\circ} \mathrm{C} / \mathrm{RU}$ of the scFv at $\mathrm{T}_{0}$. Diamonds: percentage of activity observed after incubation at $4{ }^{\circ} \mathrm{C}$. Squares: percentage of activity observed after incubation at $37 \mathrm{C}$. Lines connecting the data points are used to guide the eye of the reader.

whose expression level is the same of $\operatorname{scFv}(11 \mathrm{E})$ and $\mathrm{scFv}(\mathrm{H} 1)$. Comparison of the amino acid substitutions occurring between all the scFv intermediates showed that all clones had Phe in position H90, except for $\operatorname{scFv}(\mathrm{H} 2.1)$ that maintained the original Tyr residue. Therefore, we investigated the role of the residue occurring at position $\mathrm{H} 90$ on the expression levels of soluble scFv molecules. To this aim, we constructed a panel of mutants. In $\operatorname{scFv}\left(\mathrm{H}_{2}\right)$ and $\operatorname{scFv}(\mathrm{H} 5)$, showing low expression levels, we mutated Phe H90 to Tyr, obtaining $\mathrm{scFv}(\mathrm{H} 2) \mathrm{H} 90 \mathrm{Y}$ and $\mathrm{scFv}(\mathrm{H} 5) \mathrm{H} 90 \mathrm{Y}$, respectively. In $\mathrm{scFv}(11 \mathrm{E})$ and $\operatorname{scFv}(\mathrm{H} 1)$, showing high expression levels, we mutated Tyr H90 to Phe, obtaining scFv(11E)H90F and $\mathrm{scFv}(\mathrm{H} 1) \mathrm{H} 90 \mathrm{~F}$, respectively. The resulting expression levels of these mutants in the periplasm of E. coli are shown in Fig. 3. $\mathrm{ScFv}(\mathrm{H} 2) \mathrm{H} 90 \mathrm{Y}$ and $\mathrm{scFv}(\mathrm{H} 5) \mathrm{H} 90 \mathrm{Y}$ showed a 9 and 3.4 fold increase in the expression levels compared to the original $\mathrm{scFv}(\mathrm{H} 2)$ and $\mathrm{scFv}(\mathrm{H} 5)$, respectively, while $\mathrm{scFv}(11 \mathrm{E}) \mathrm{H} 90 \mathrm{~F}$ and $\mathrm{scFv}(\mathrm{H} 1) \mathrm{H} 90 \mathrm{~F}$ showed a 2.6 and 3.3 fold decrease compared to $\mathrm{scFv}(11 \mathrm{E})$ and $\mathrm{scFv}(\mathrm{H} 1)$, respectively. The purification yield of $\operatorname{scFv}(\mathrm{H} 2) \mathrm{H} 90 \mathrm{Y}$ 
was about $600 \mu \mathrm{g} / \mathrm{L}$ of bacterial culture, and the yield of $\mathrm{scFv}(\mathrm{H} 5) \mathrm{H} 90 \mathrm{Y}$ about $450 \mu \mathrm{g} / \mathrm{L}$ of bacterial culture, i.e. more than 10-fold higher than that of $\mathrm{scFv}(\mathrm{H} 5)$.

Affinity measurements of the humanized $\mathrm{scFv}(\mathrm{H} 5)$ H9OY towards HEL by surface plasmon resonance: The binding activity of the humanized $\mathrm{scFv}(\mathrm{H} 5) \mathrm{H} 90 \mathrm{Y}$ for HEL was analysed by surface plasmon resonance (SPR). The calculated association and dissociation rate constants were $1.45 \times 10^{4} \mathrm{M}^{-1} \mathrm{~s}^{-1}$ and $1.05 \times 10^{-3}$ $\mathrm{s}^{-1}$ respectively, giving a $\mathrm{K}_{D}$ of $72 \mathrm{nM}$, similar to, and even better than, that measured for the cognate $\operatorname{scFv}(11 \mathrm{E})\left(\mathrm{K}_{D}=105 \mathrm{nM}\right)$ [10]. The binding activity of the reduced $\mathrm{scFv}(\mathrm{H} 5) \mathrm{H} 90 \mathrm{Y}$ was also calculated by SPR. The scFv was subjected to strongly reducing conditions (DTT $12.5 \mathrm{mM}$ ) and its reduced state was confirmed by gel-shift analysis on a non reducing SDSPAGE. The calculated association and dissociation rate constants were $2.83 \times 10^{4} \mathrm{M}^{-1} \mathrm{~s}^{-1}$ and $2.71 \times 10^{-3}$ $\mathrm{s}^{-1}$, respectively, giving a $\mathrm{K}_{D}$ of $96 \mathrm{nM}$, which is essentially the same as that calculated for the non reduced form.

Serum stability of the humanized $s c F v$ : For clinical applications recombinant antibodies must be resistant towards human serum proteases and retain their activity at $37^{\circ} \mathrm{C}$ (body temperature). We assessed the stability of the $\mathrm{scFv}(\mathrm{H} 5) \mathrm{H} 90 \mathrm{Y}$ by measuring its binding to HEL by SPR after incubation at $37^{\circ} \mathrm{C}$ in human serum or in $\mathrm{PBS}$, for various time periods. As reference molecules we used the $\operatorname{scFv}(11 \mathrm{E})$, previously shown to be endowed with high thermodynamic stability [10], and the $\mathrm{scFv}(\mathrm{D} 1.3)$ having standard thermodynamic properties. As shown in Fig. 4, scFv(11E) retained $90 \%$ and $65 \%$ of its binding activity when incubated for seven days at $37^{\circ} \mathrm{C}$ in PBS (panel A) and in human serum (panel B) respectively, whereas $\mathrm{scFv}(\mathrm{D} 1.3)$ lost more than $90 \%$ of its activity after just one day of incubation at $37^{\circ} \mathrm{C}$ in both media. The $\mathrm{scFv}(\mathrm{H} 5) \mathrm{H} 90 \mathrm{Y}$ retained $66 \%$ of its binding activity after seven days incubation at $37^{\circ} \mathrm{C}$ both in PBS (Fig. 4A) and in human serum (Fig. 4B), indicating that its stability in human serum is essentially the same of the highly thermodynamically stable parent $\mathrm{scFv}(11 \mathrm{E})$.

Conclusions: Because of its stability in human serum, both under oxidising and reducing conditions, and of its potentially low immunogenic properties, the scFv(H5)H90Y scaffold obtained in this work represents an ideal candidate to produce highly stable chimeric scFv molecules for extra- and intra-cellular applications in human therapy and in vivo diagnosis, by either combinatorial methods (i.e., construction of new libraries based on this scaffold) or rationally designed
ABS grafting from an ABS-donor $\mathrm{Ab}$ or $\mathrm{Ab}$ fragment of known $\mathrm{V}_{L}$ and $\mathrm{V}_{H}$ sequence against a required antigen.

\section{References}

[1] P. Holliger and P.J. Hudson, Engineered antibody fragments and the rise of single domains, Nat Biotechnol 23 (2005), 1126-1136.

[2] R.E. Bird, K.D. Hard man, J.W. Jacobson, S. Johnson, B.M. Kaufman, S.M. Lee, T. Lee, S.H. Pope, G.S. Riordan and M. Whitlow, Single-chain antigen-binding proteins, Science 242 (1988), 423-426.

[3] K. Proba, A. Wörn, A. Honegger and A. Plückthun, Antibody $\mathrm{scFv}$ fragments without disulphide bonds made by molecular evolution, J Mol Biol 275 (1998), 245-253.

[4] P. Tavladoraki, A. Girotti, M. Donini, F.J. Arias, C. Mancini, V. Morea, R. Chiaraluce, V. Consalvi and E. Benvenuto, A single-chain antibody fragment is functionally expressed in the cytoplasm of both Escherichia coli and transgenic plants, Eur J Biochem 62 (1999), 617-624.

[5] A. Wörn, A. Auf der Maur, D. Escher, A. Honegger, A.Barberis and A. Plückthun, Correlation between in vitro stability and in vivo performance of anti-GCN4 intrabodies as cytoplasmic inhibitors, J Biol Chem 275 (2000), 2795-2803.

[6] F. Liu, M. Kumar, Q. Ma, M. Duval, D. Kuhrt, R. Junghans, M. Posner and L. Cavacini, Human single-chain antibodies inhibit replication of human immunodeficiency virus type 1 (HIV-1), AIDS Res Hum Retroviruses 21 (2005), 876-881.

[7] C.A. Leath, J.T. Douglas, D.T. Curiel and R.D. Alvarez, Single-chain antibodies: A therapeutic modality for cancer gene therapy, Int J Oncol 24 (2004), 765-771.

[8] G. Pavlinkova, D. Colcher, B.J. Booth, A. Goel, U.A. Wittel and S.K. Batra, Effects of humanization and gene shuffling on immunogenicity and antigen binding of anti-TAG-72 singlechain Fvs, Int J Cancer 94 (2001), 717-726.

[9] M. Donini, V. Morea, A. Desiderio, D. Pashkoulov, M.E. Villani, A. Tramontano and E. Benvenuto, Engineering stable cytoplasmic intrabodies with designed specificity, J Mol Biol 330 (2003), 323-332.

[10] A. Desiderio, R. Franconi, M. Lopez, M.E. Villani, F. Viti, R. Chiaraluce, V. Consalvi, D. Neri and E. Benvenuto, A semisynthetic repertoire of intrinsically stable antibody fragments derived from a single-framework scaffold, J Mol Biol 310 (2001), 603-615.

[11] T. Murata, S. Fushinobu, M. Nakajima, O. Asami, T. Sassa, T. Wakagi and I. Yamaguchi, Crystal Structure of the Liganded Anti-Gibberellin A(4) Antibody 4-B8(8)/E9 Fab Fragment Biochem, Biophys Res Comm 293 (2002), 489-496.

[12] M. Karpusas, J. Lucci, J. Ferrant, C. Benjamin, F.R. Taylor, K. Strauch, E. Garber and Y.M. Hsu, Structure of Cd40 Ligand in Complex with the Fab Fragment of a Neutralizing humanized Antibody, Structure 19 (2001), 321-329.

[13] C. Chotia and A.M. Lesk, Canonical structures for the hypervariable regions of immunoglobulins, J Mol Biol 196 (1987), 901-917.

[17.10-17.30]

Human antibodies selected by phage display as potent and selective protease inhibitors 
S. Schoonbroodt, D. Sexton*, A.E. Nixon*, L. Devy, K. Rookey, M. Vanhove, D. Dransfield*, R.C. Ladner*, C.R. Wood and R.M. Hoet

Dyax S.A., Bld Du Rectorat 27b-B22, Sart-Tilman, B-4000 Liege, Belgium

${ }^{*}$ Corresponding author: Dyax Corp. Cambridge, Ma, Usa. Tel.: +32 436424 45; E-mail:

sschoonbroodt@Dyax.Com.

Introduction: The control of proteolysis in an organism is achieved under normal circumstances through a balance of protease production, degradation and inactivation by inhibitors. Unregulated or dysregulated protease activities can result in the onset or progression of disease. A number of proteases, such as members of the matrix metalloproteinase (MMPs) and serine protease families, have been validated as potential therapeutic targets in inflammatory disorders, tumor growth and metastasis [1,2].

Matrix metalloproteinases (MMPs): Belong to the metzincin superfamily that includes more than 20 zinc-dependent enzymes sharing common features [3]. Their structure is composed of three domains, a prodomain that is removed upon activation, a catalytic domain responsible for hydrolytic activity, and a hemopoxin-like domain that is probably playing a role in substrate recognition. The regulation of MMPs occurs at both a level of expression, activation, localization, and TIMP inhibition [4]. MMPs recognize diverse substrates that extend beyond extracellular matrix components, also regulating other pro-MMPs. Since their substrates are diverse, MMPs are involved in variety of homeostatic functions, such as bone remodeling, wound healing, and several aspects of immunity. However, overexpressed or misregulated MMPs are involved in a number of pathological processes, such as tumor progression, fibrosis, chronic inflammation, tissue destruction [5,6].

Here, we will describe the work on two MMP members, the secreted MMP-26 and the membrane-type MMP-14. MMP-26 (also know as endometase and matrilysin-2) has not yet been extensively studied, except for its tissue localization and substrate identification [7]. Interest in this protease as a potential therapeutic candidate has emerged from work showing its overexpression in cancers of epithelial origin of the endometrium, prostate, and mammary gland $[8,9,10]$. MMP-14 (MT1-MMP) is the prototypic member of the membrane-type MMP (MT-MMP) subgroup [11]. MMP-14 regulates the activation of pro-MMP2 and pro-MMP13. Its overexpression has been associated with various pathological conditions and MMP-14 is proposed to play important roles in tumor progression by promoting cell invasion, angiogenesis and matrix degradation [6].

Serine proteases are a class of peptidases characterized by the presence of a serine residue in the active site of the enzyme. They participate in a wide range of functions in the body, including blood clotting, immunity, and inflammation, as well as contributing to digestive enzymes. Serine proteases are naturally inhibited by proteins called "serpins" by forming a covalent bond with the serine protease. The best-studied serpins are antithrombin and A1-antitrypsin, known for their role in coagulation/thrombosis and emphysema respectively [12]. In this paper, we will report work on human kallikrein 1 (hK1), a member of the kallikrein serine protease subgroup. The role of $\mathrm{hK} 1$ is demonstrated in establishement of preclinical models of asthma and as such is a potential target in the treatment of airway inflammatory diseases [13].

Protease inhibitors as potential drugs: Although interest in protease inhibition started about 15 years ago, there are relatively few marketed protease inhibitors. The majority of drug discovery efforts in this field were devoted to small molecule drugs. There has been success with HIV protease and ACE inhibition, but many others such as MMP-inhibitors failed to give expected results either because of lack of efficacy or severe sideeffects observed during clinical trials [2]. Structural similarities within the active site of most proteolytic enzyme families result in the majority of small molecule protease inhibitors being able to inhibit some related family members of the target protease. The key challenge in future discovery of protease inhibitor drugs will be to identify potent and specific inhibitors of proteases. The next generation of therapeutic drug candidates against proteases is likely to consist of neutralizing antibodies identified from phage display libraries of human antibody fragments. The large surface area of interaction of an antibody with its antigen provides the molecular basis for obtaining highly selective protease inhibitors.

Phage display technology: Phage display allows rapid isolation of fully human target-specific antibodies from a library of billions of different antibodies. In addition since it is an in vitro process, it is possible to obtain antibodies to human targets that are toxic, non immunogenic, immunosuppressive, or identical to mouse proteins. The antibody phage display libraries used here are a phagemid or a phage system (known as the Dyax FAB-310 and FAB-410 libraries) 
a. DEPLETION

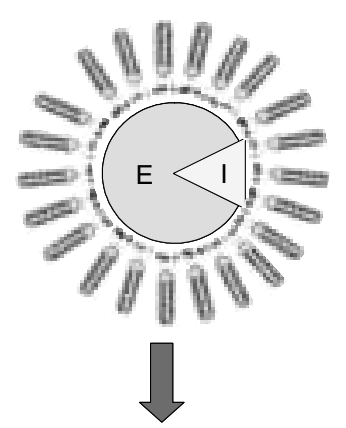

b. SELECTION

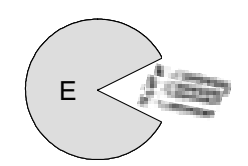

c. ELUTION

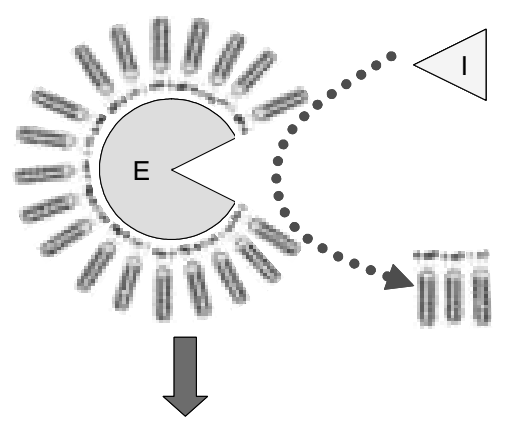

d. SCREENING

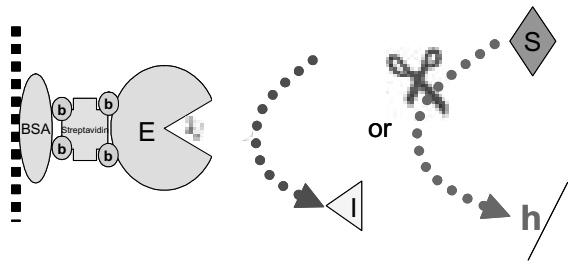

Fig. 1. Selection and screening strategies designed to obtain FAB protease inhibitors. (A) Depletion with enzyme (E): Inhibitor (I) Complexes is followed by (B) Selection on the active enzyme; (C) Elution with inhibitors (I) (D) Screening FABS by competition with inhibitors. B = Biotin group, $\mathrm{I}=$ inhibitor, $\mathrm{S}=$ substrate.

that display antibody Fab fragments fused to the M13 gene III protein. The antibody repertoire contains VL sequences, captured from a diverse population of normal and autoimmune human donors, randomly paired with VH sequences that combine within one V-gene as scaffold (VH3-23) synthetic diversity at functional sites within the VH-CDR1/2 and a non-immune VHCDR3 diversity. This library has been shown to be successful on multiple targets and routinely produces high-affinity antibodies $(\mathrm{KD}<1 \mathrm{nM})$ without the need for time-consuming affinity maturation [14]. The vector system used in this library has a modular design that allows a straightforward transfer of Fab cassettes into different expression vectors for soluble Fab and IgG of various classes [15].

Using Dyax's phage and phagemid: Fab libraries, we have identified selective and potent inhibitors of both serine and metalloproteinases. Their discovery and characterization are described below in more detail.

Discovery of protease inhibitor: Selection strategy design - $\mathrm{aC}$ The standard selection process involves the exposure of the antibody phage library to the targeted protein, resulting in a collection of different antibodies that recognize a large panel of epitopes at the antigen surface. Driving the selection to a specific epitope on the target might help homing in to antibodies with the desired specificity. In the case of enzyme inhibition, the specific epitope to recognize is the active site of

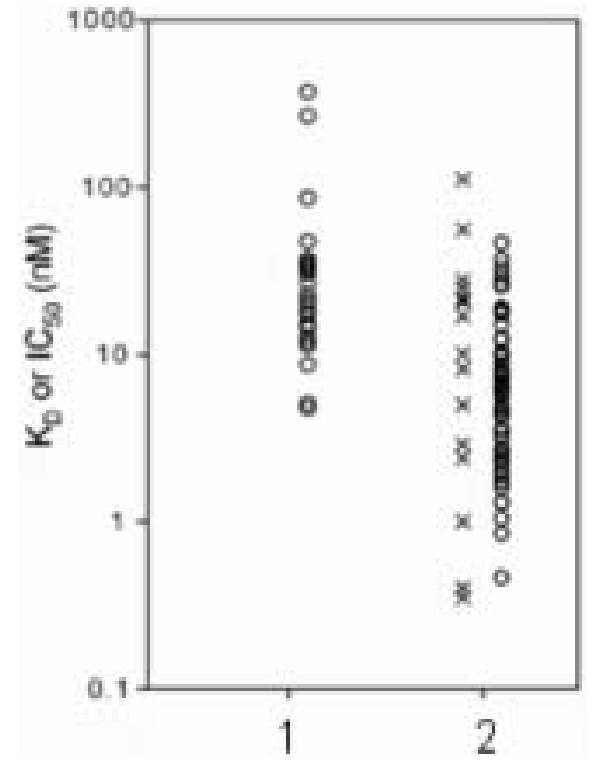

Fig. 2. Range of FAB antibody fragment affinities inhibiting the HK1 sering protease after selecting without (1) Or with (2) A depletion procedure using the HK1-Inhibitor complex. Open circles are $\mathrm{K}_{D}$ values and crosses are $\mathrm{IC}_{50}$ estimates.

the protein, known as the catalytic domain. It is well known that an enzyme is regulated in vivo by binding to its natural inhibitor, preventing the substrate from binding the active catalytic domain. Based on this con- 
cept, we have designed selection strategies to target only the active catalytic domain (Fig. 1a,b,c). Using an enzyme-inhibitor complex in first instance of the selection depletes the library for non-inhibiting antibodies that recognize surface structural epitopes of the target but not the active site; the inhibitor (I) prevents the binding of antibodies to the catalytic domain of the enzyme (E) (Fig. 1a). After library depletion for noninhibiting binders, the library can then be selected on the active enzyme only to capture antibodies recognizing the remaining epitopes, i.e. present on the catalytic domain (Fig. 1b). This strategy followed for the hK1 enzyme was shown to provide more antibodies with inhibition properties than straightforward standard selection methods as presented in Figure 2. Target expression and detailed selection procedure are described elsewhere [16]. The probability of finding inhibitors with improved KD or IC50 is consequently increased in such selection outputs. A similar strategy was followed to select Fab using MMPs in complex with their natural inhibitor TIMP-2 in an initial depletion step. Another strategy followed for the recovery of antibodies specific for the catalytic domain can be achieved through an elution step that uses a known inhibitor as a binding competitor (Fig. 1c). This strategy was also used for hK1 (aprotinin) and MMP-14 (TIMP-2) but was found to be less effective that the strategy using the E-I complex in depletion (data not shown).

Screening strategies for binding activity: The introduction of automated primary screening methods to the phage display process provides the opportunity to evaluate hundreds of Fabs in downstream assays $[17,18]$. In this study, the initial screening step was performed by automated enzyme-linked immunosorbent assay (ELISA) in medium (MMP-26) or high throughput mode (MMP-14, hK1). Sorting for binders to the catalytic domain can also be done by ELISA using the natural inhibitor as competitor in the assay (Fig. 1d). Further characterization of the antibodies is initiated once a set of unique clones is defined.

Cell-based and indirect screening strategies for inhibition: A total of 68 unique Fabs were converted to the huIgG4 format and characterized for their properties to inhibit the activity of the MMP-26 enzyme. To achieve this, two indirect assays were developed. The first one monitored the invasion of a cancer cell line in presence or absence of the anti-MMP-26 Fabs. Nine Fab antibodies were shown to decrease the JEG-3 cell invasion in vitro with IC50<50nM. The second assay exploited the property of MMP-26 to cleave pro-MMP-9 into active MMP-9, monitoring the cleavage of a peptide sub- strate. Two antibodies were shown to be able to block MMP-26-induced MMP-9 activity.

Screening strategies for inhibition and potency: The rapid discovery of the most potent antibodies identified in the primary screen depends on the development and use of suitable secondary assays. For MMP-14, steadystate enzyme inhibition assays using Phytip purified Fabs were directly performed as secondary screen on 70 unique Fabs, looking for cleavage inhibition of a small fluorescent quenched peptide substrate (Fig. 1d). A total of 16 inhibitors were identified. Further characterization of enzyme inhibitors was performed by the measurement of their IC50 towards the enzyme using IgGs. This step is a lenghtly process compared to other automated steps developed for phage display since it requires the evaluation of the antibody inhibition property using different antibody concentrations. Two out of the 16 MMP-14 inhibitors were found to have IC50 in the subnanomolar range.

In case of $\mathrm{hK} 1,355$ unique Fab binders were first ranked using surface plasmon resonance microarrays prior to IC50 determination [16]. Thirty five inhibitors were found with two of them having IC50 $<1 \mathrm{nM}$.

IC50 ranking of the different antibodies early in drug discovery accelerates the lead discovery. We have used a procedure that combines semi-automated Fab purification with medium throughtput IC50 determination of Fabs. The VH3-23 scaffold used in this library binds to protein A. This property was exploited to develop a semi-automated protein purification procedure of Fab fragments. Fab fragments are produced in $5 \mathrm{~mL}$ bacterial culture supernatants in 24-well plates and sequentially purified in solution using protein A coupled to magnetic beads. The recovered protein amount average is about $5 \mu \mathrm{g}$ per sample. The concentration of the set of Fab protein preparations is first assessed by $\mathrm{Bi}$ acore using a protein A coated chip [19], then normalized among the samples. The screening for inhibitors is subsequently performed as described above using a fluorescent quenched substrate.

Screening for selectivity and specificity: Depending on the need for crossreactive antibodies to other species counterparts of the target (most often mouse), the selection strategies can include the use of the mouse protein, driving the selections to antibodies that recognize common epitopes present on both targets. In case the targets are homologous, alternation of the targets during selection might not be necessary. The specificity to each target is analyzed by ELISA and inhibition assays. Finally, the antibodies are verified for their selectivity by measuring their inhibition of a panel of related proteases. 
Conclusions: The combination of human Fab phage display libraries and automation provides a means to identify rapidly high affinity lead candidates. A variety of techniques can be used in the selection process to enrich the Fab output for protease inhibitors. Antibodies represent a new generation of selective protease inhibitors.

\section{References}

[1] C.M. Overall and O. Kleifeld, Nat Rev Cancer 6(3) (2006), 227-239.

[2] B. Turk, Nat Rev Drug Discov 5(9) (2006), 785-799.

[3] M.D. Sternlicht and Z. Werb, Annu Rev Cell Dev Biol 17 (2002), 463-516.

[4] P. Borden and R.A. Heller, Crit Rev Eukaryot Gene Expr 7(12) (1997), 159-178.

[5] A.J. Barrett, N.D. Rawlings and J.F. Woessner, Handbook of Proteolytic enzymes, Academic Press Ed., Academic Press, London, 2004.

[6] M. Egeblad and Z. Werb, Nat Rev Cancer 2(3) (2002), 161174.

[7] H.I. Park, B.E. Turk, F.E. Gerkema, L.Z. Cantley and Q.X. Sang, J Biol Chem 277(38) (2002), 35168-35175.

[8] A.B. de Coignac, G. Elson, Y. Delneste, G. Magistrelli, P. Jeannin, J.P. Aubry, O. Berthier, D. Schmitt, J.Y. Bonnefoy and J.F. Gauchat, Eur J Biochem 267(11) (2000), 3323-3329.

[9] H.I. Park, J. Ni, F.E. Gerkema, D. Liu, V.E. Belozerov and Q.X. Sang, J Biol Chem 275(27) (2000), 20540-20544.

[10] J.A. Uria and C. Lopez-Otin, Cancer Res 60(17) (2000), 47454751.

[11] I. Yana and M. Seiki, Clin Exp Metastasis 19(3) (2002), 209215.

[12] A.T. Mulgrew, C.C. Taggart and N.G. McElvaney, Lung 185(4) (2007), 191-201.

[13] S.C. Christiansen, D. Proud, R.B. Sarnoff, U. Juergens, C.G. Cochrane and B.L. Zuraw, Am Rev Respir Dis 145(4 Pt 1) (1992), 900-905.

[14] R.M. Hoet, E.H. Cohen, R.B. Kent, K. Rookey, S. Schoonbroodt, S. Hogan, L. Rem, N. Frans, M. Daukandt, H. Pieters, R. van Hegelsom, N.C. Neer, H.G. Nastri, I.J. Rondon, J.A. Leeds, S.E. Hufton, L. Huang, I. Kashin, M. Devlin, G. Kuang, M. Steukers, M. Viswanathan, A.E. Nixon, D.J. Sexton, H.R. Hoogenboom and R.C. Ladner, Nat Biotechnol 23(3) (2005), 344-348.

[15] T. Jostock, M. Vanhove, E. Brepoels, R. Van Gool, M. Daukandt, A. Wehnert, R. Van Hegelsom, D. Dransfield, D. Sexton, M. Devlin, A. Ley, H. Hoogenboom and J. Mullberg, J Immunol Methods 289(1-2) (2004), 65-80.
[16] D. Wassaf, G. Kuang, K. Kopacz, Q.L. Wu, Q. Nguyen, M. Toews, J. Cosic, J. Jacques, S. Wiltshire, J. Lambert, C.C. Pazmany, S. Hogan, R.C. Ladner, A.E. Nixon and D.J. Sexton, Anal Biochem 351(2) (2006), 241-253.

[17] R.M. de Wildt, C.R. Mundy, B.D. Gorick and I.M. Tomlinson, Nat Biotechnol 18(9) (2000), 989-994.

[18] J. Hallborn and R. Carlsson, Biotechniques Suppl (2002), 3037.

[19] M. Steukers, J.M. Schaus, R. van Gool, A. Hoyoux, P. Richalet, D.J. Sexton, A.E. Nixon and M. Vanhove, J Immunol Methods 310(1-2) (2006), 126-135.

\section{[17.30-17.50]}

Trends in scientific \& patent production on antibodies and related technologies

\section{Luca Falciola}

Intellectual Property \& Collaborative Research RiboVax Biotechnologies SA http://www.ribovax.com 12 avenue des Morgines 1213 Petit-Lancy, Geneva Switzerland Direct +41228791126

Tel.: +41228791122; Fax: +41228791124 cell +417981840 56; E-mail:

Luca.Falciola@ ribovax.com

Journals, industry reports, company communications, and conferences such as Human Antibodies \& Hybridomas, regularly show the growth in the number of antibodies that old and new technologies allow to generate, identify, produce, and/or characterize. Many databases and search techologies give the possibility to extract, from the large body of scientific \& patent publications on these subjects, the information that can be potentially relevant for taking decisions of scientific, technical, commercial, or legal importance. The presentation will provide some examples on how trends in scientific \& patent production on antibody-related technologies and products can be generated using appropriate search strategies and what such analyses can tell on the state of the industry. 